Supporting Information

\title{
Palladium Nanoparticle-Decorated Mesoporous Polydopamine/Bacterial Nanocellulose as a Catalytically Active Universal Dye Removal Ultrafiltration Membrane
}

Hamed Gholami Derami ${ }^{\dagger}$, Prashant Gupta ${ }^{\dagger}$, Rohit Gupta ${ }^{\dagger}$, Priya Rathi ${ }^{*}$, Jeremiah J. Morrissey ${ }^{\S}$, and Srikanth Singamaneni ${ }^{\dagger *}$

†. Department of Mechanical Engineering and Materials Science, Institute of Materials Science and Engineering, Washington University in St. Louis, Saint Louis, MO 63130, USA

$\S$. Department of Anesthesiology, Siteman Cancer Center, Washington University in St. Louis, St. Louis, MO, 63110, USA

¥. Department Chemistry, Washington University in St. Louis, Saint Louis, MO 63130, USA

\section{Author Information}

Corresponding Authors

^E-mail: singamaneni@wustl.edu 
Gold nanoparticle (AuNP) synthesis: AuNPs were synthesized using a seedmediated method. ${ }^{1}$ Au seeds with a diameter of $3 \mathrm{~nm}$ were synthesized by addition of ice-cold sodium borohydride $(0.6 \mathrm{ml}, 10 \mathrm{mM})$ into a mixture of hexadecyltrimethylammonium bromide CTAB $(9.75 \mathrm{ml}, 0.1 \mathrm{M})$ and gold chloride trihydrate $(0.25 \mathrm{ml}, 10 \mathrm{mM})$ under vigorous stirring. AuNPs with a dimeter of $5 \mathrm{~nm}$ were synthesized by mixing CTAC ( $2 \mathrm{ml}, 0.2 \mathrm{M})$, ascorbic acid $(1.5 \mathrm{ml}, 0.1 \mathrm{M})$ and $3 \mathrm{~nm}$ asprepared seed $(1 \mathrm{ml})$ and addition of gold chloride solution $(2 \mathrm{ml}, 0.5 \mathrm{mM})$ under vigorous stirring for 15 minutes. For $10 \mathrm{~nm}$ AuNPs, CTAC (7 ml, $0.2 \mathrm{M})$, ascorbic acid $(5.25 \mathrm{ml}, 0.1 \mathrm{M})$ and $3 \mathrm{~nm}$ as-prepared seed $(0.175 \mathrm{ml})$ were mixed and added with gold chloride solution ( $7 \mathrm{ml}, 0.5 \mathrm{mM}$ ) under vigorous stirring for 15 minutes.

Thermogravimetric Analysis (TGA): Thermogravimetric analysis (TGA) was employed to analyze the mass loading of $\mathrm{Pd}$ in Pd-BNC and Pd-mPDA-BNC membranes (Figure S3). For Pd-mPDA-BNC, the first mass loss of $\sim 6 \%$ can be attributed to residual/absorbed water at $100{ }^{\circ} \mathrm{C}$, second mass loss of $\sim 6 \%$ at $280{ }^{\circ} \mathrm{C}$ can be attributed to the degradation of cellulose and mPDA particles and a mass loss of $\sim 30 \%$ at $350^{\circ} \mathrm{C}$ can be attributed to the decomposition of cellulose residue, which generates $\mathrm{CO}_{2}$ and $\mathrm{H}_{2} \mathrm{O}$, and further degradation of mPDA particles. ${ }^{2}$ After heating to $600{ }^{\circ} \mathrm{C}$, the remaining mass $(\sim 46 \%)$ is composed of $\mathrm{Pd}$ nanoparticles and carbon residues. The mass of carbon residues for $\mathrm{mPDA}-\mathrm{BNC}$ at $600^{\circ} \mathrm{C}$ is $\sim 25.7 \%$. Based on the above discussion, the mass loading of $\mathrm{Pd}$ in Pd-mPDA-BNC membrane was calculated to be $\sim 20.3 \mathrm{wt} \%$. However, in the case of Pd-BNC, the mass loading of Pd was calculated to be $\sim 13.6$ wt $\%$. 
Environmental Impact of Sodium Borate: Environmental Protection Agency's (EPA) guidelines states that Lowest Observed Adverse Effect Level (LOAEL) for oral exposure (e.g. drinking) of boric acid and sodium borate is between $32 \mathrm{mg} / \mathrm{kg} /$ day and $46 \mathrm{mg} / \mathrm{kg} /$ day. ${ }^{5}$ LOAEL shows the lowest dose at which there was an observed toxic or adverse effect. By assuming that a toddler has an average weight of $15 \mathrm{~kg}$ and drinks 2 liters of water every day, the LOAEL limit would be between $480 \mathrm{mg}$ and 690 mg. In our experiments, maximum final concentration of $\mathrm{NaBH}_{4}$ is $2.5 \mathrm{mM}$ and by assuming that $100 \%$ of it has reacted and turned into sodium borate, 2 liters of filtered water contain $329 \mathrm{mg}$ of sodium borate, which is below the lower limit of LOAEL. 

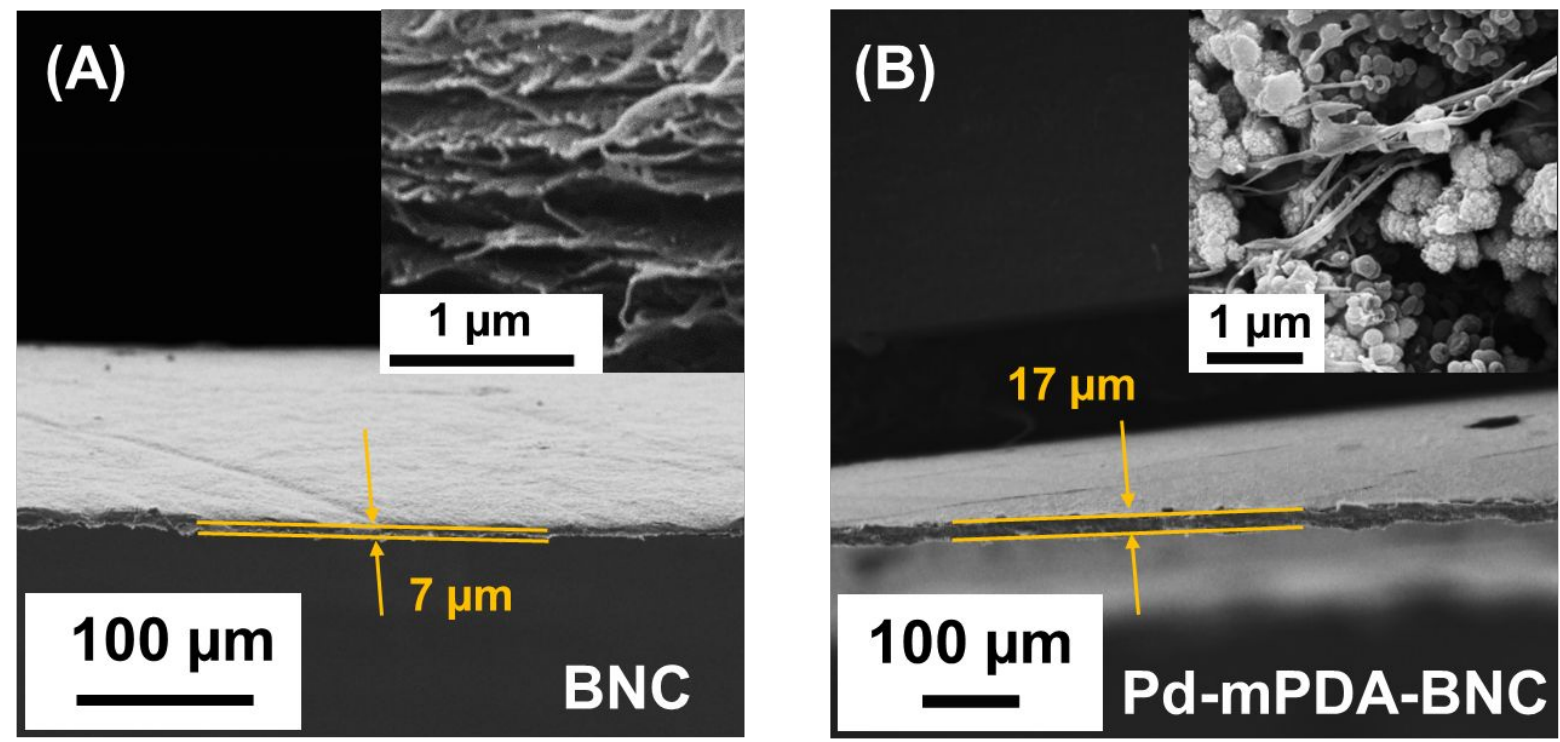

Figure S1. Cross section SEM images of the (A) BNC membrane and (B) Pd-mPDABNC membrane. (Insets show corresponding higher magnification SEM images. ) 

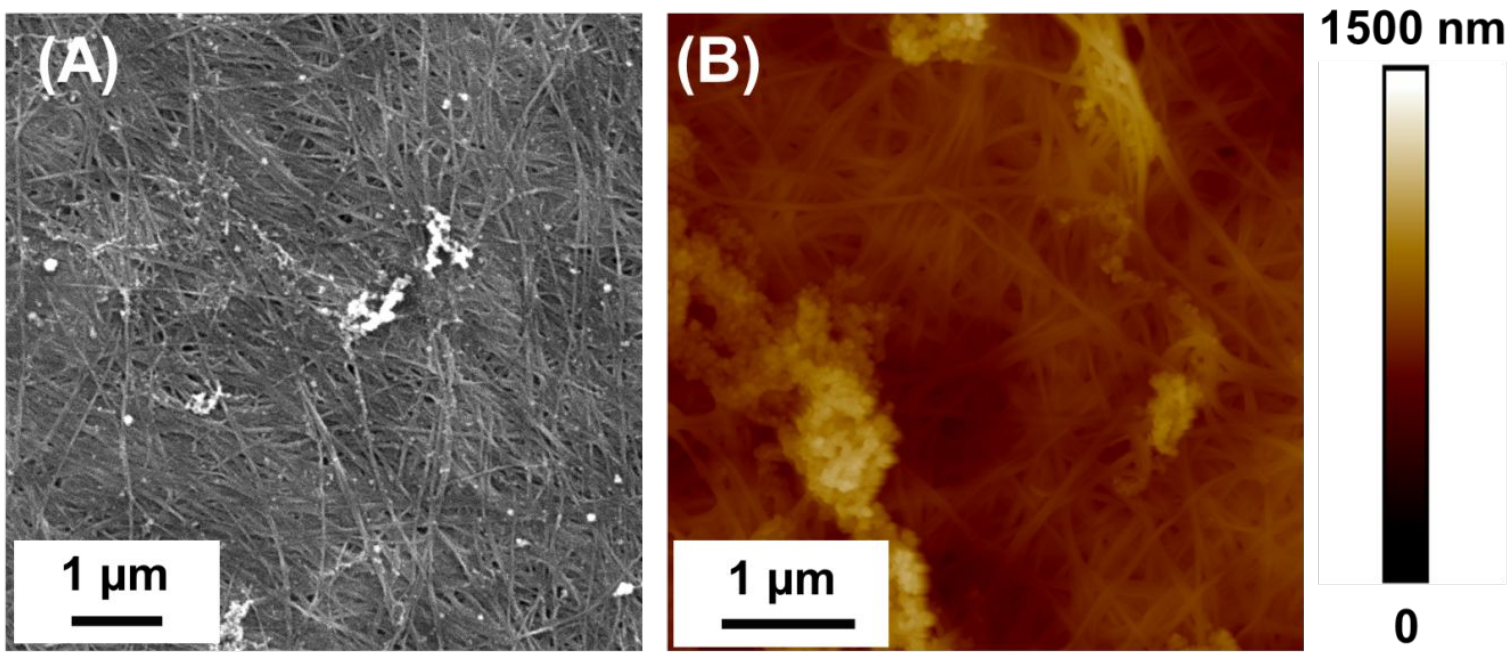

Figure S2. (A) SEM and (B) AFM images of the surface of the Pd-BNC membrane. 


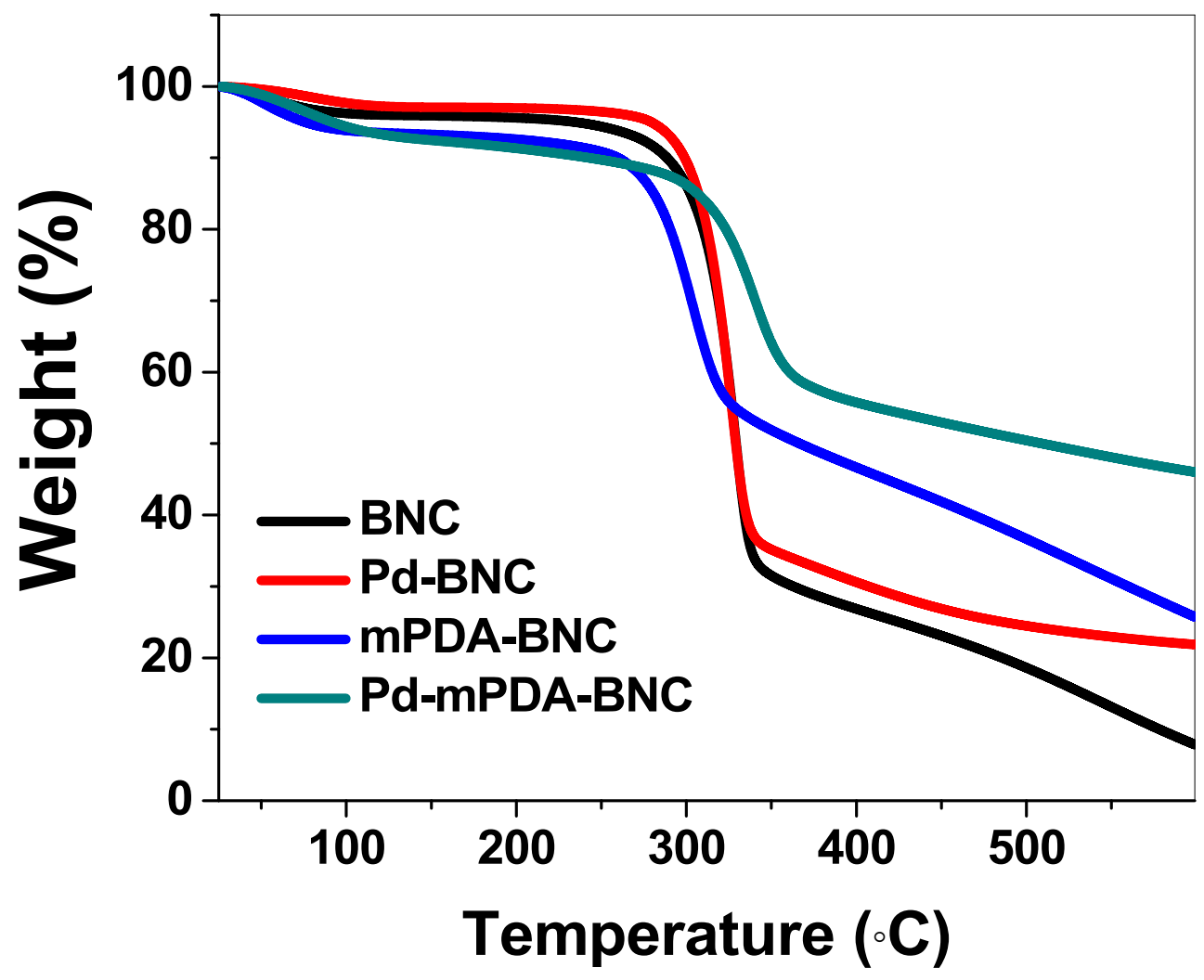

Figure S3. Weight loss profiles of BNC, Pd-BNC, mPDA-BNC and Pd-mPDA-BNC composites obtained by TGA. 


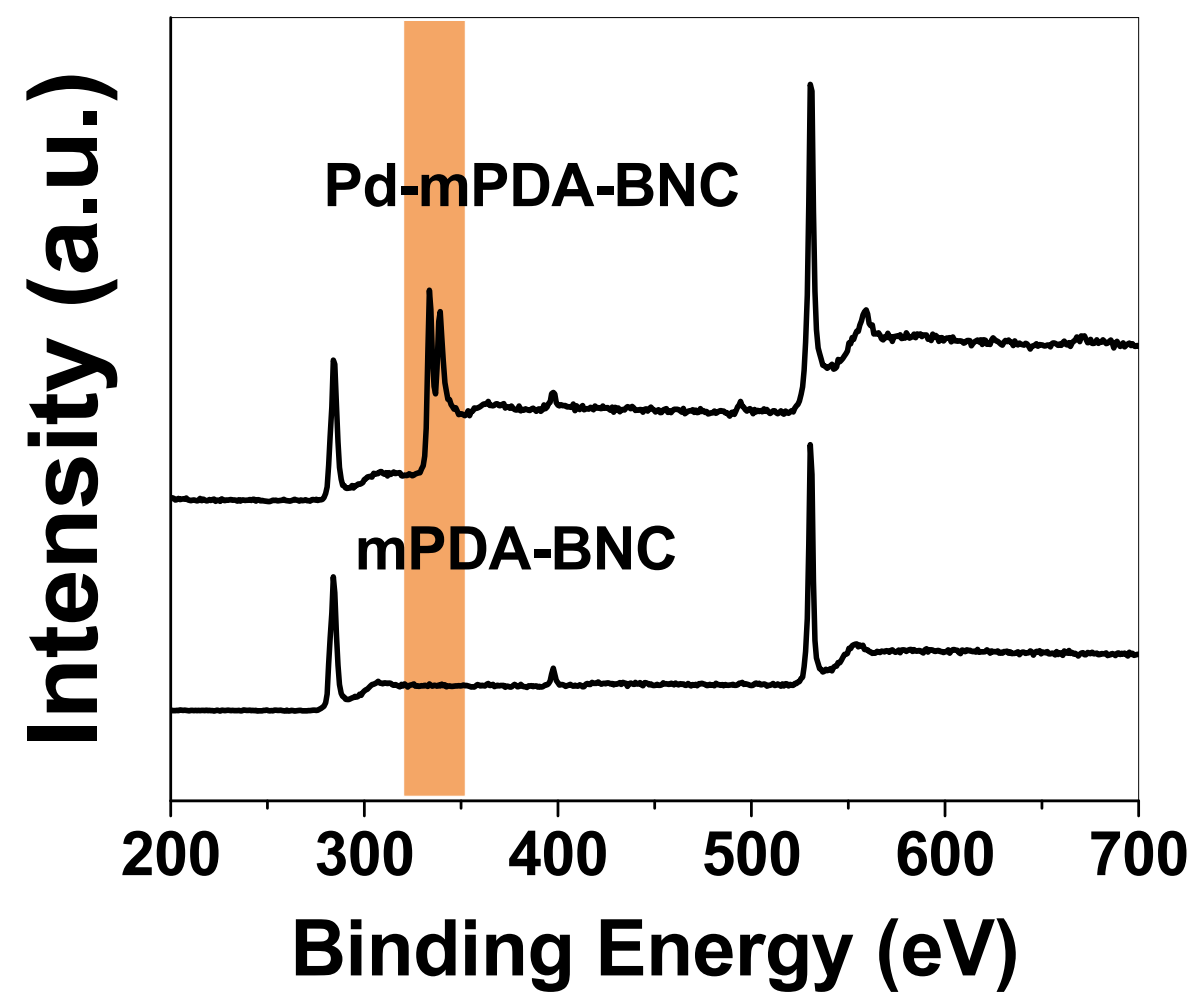

Figure S4. XPS spectra of mPDA-BNC and Pd-mPDA-BNC membranes confirming the presense of metallic $\mathrm{Pd}$. 
(A)

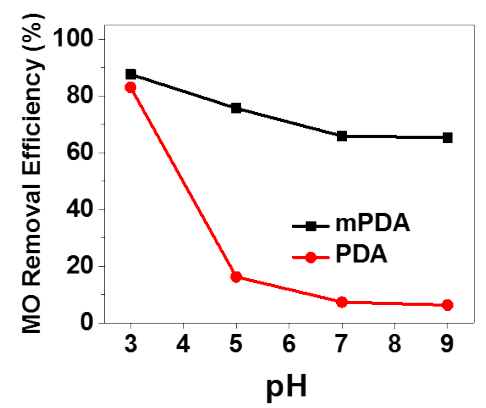

(B)

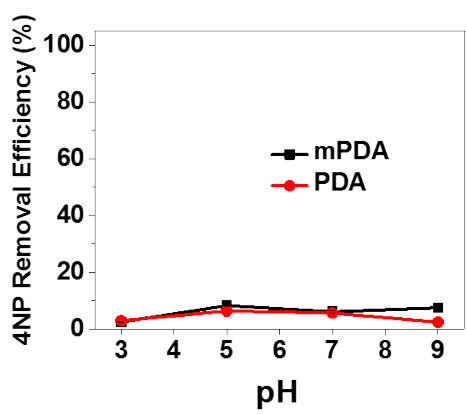

(C)

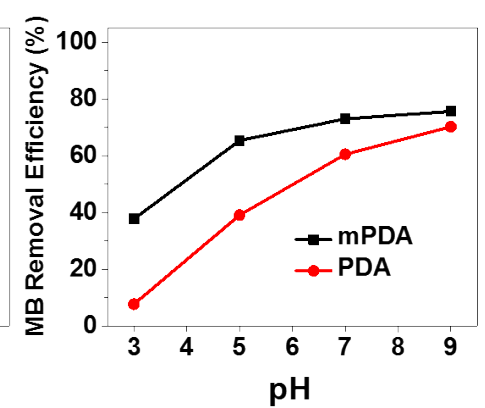

Figure S5. mPDA vs PDA nanoparticle efficiency in removing (A) MO, (B) 4NP and (C) $\mathrm{MB}$ at different $\mathrm{pH}$ values. 


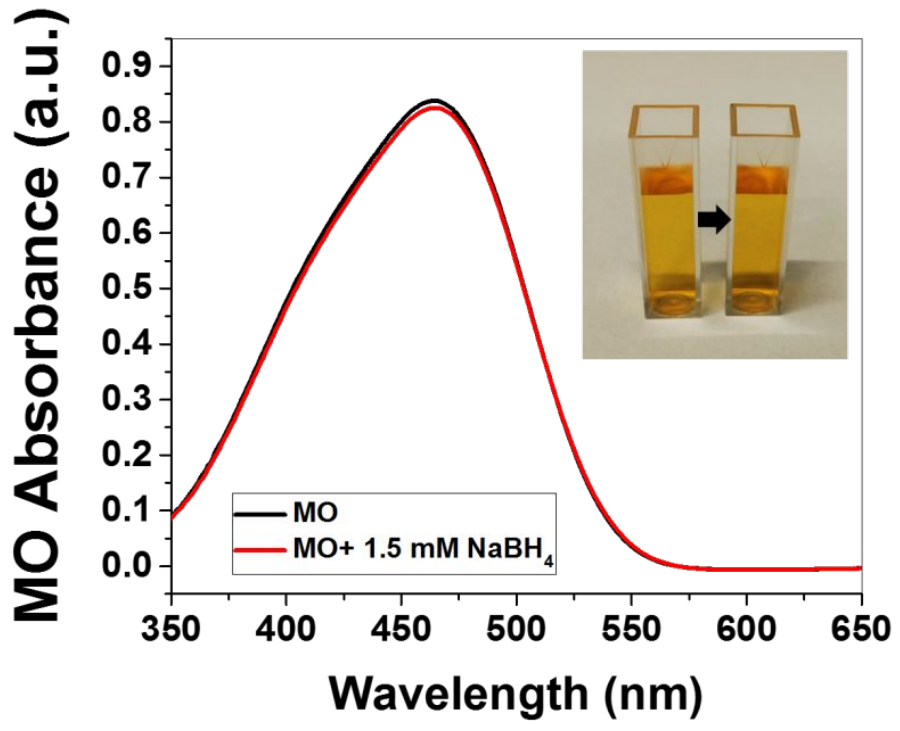

Figure S6. Effect of $1.5 \mathrm{mM} \mathrm{NaBH}_{4}$ on the absorbance of the $\mathrm{MO}$ after 20 minutes. 
(A)

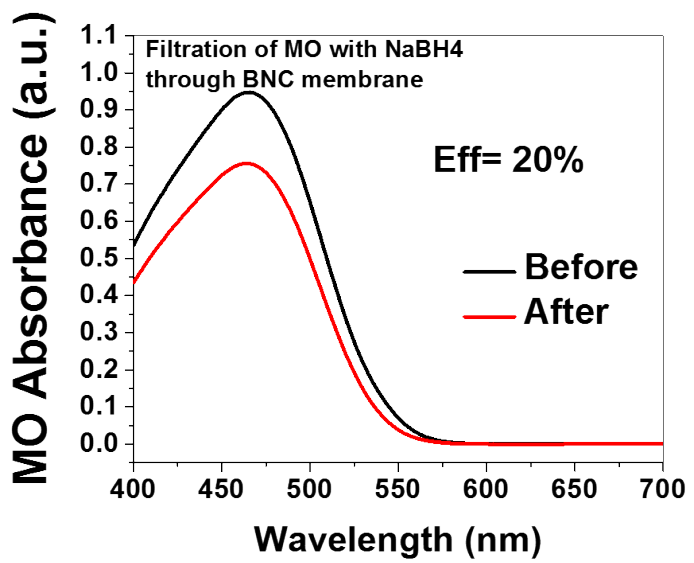

(B)

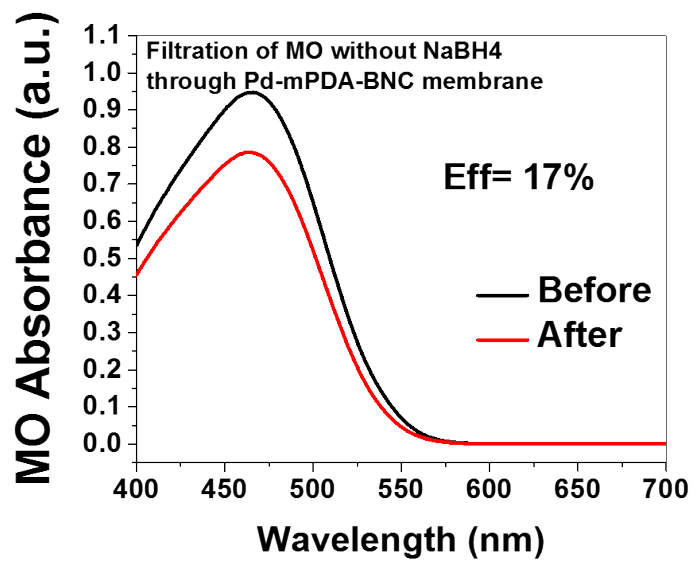

Figure S7. (A) Absorbance of $\mathrm{MO}$ solution before and after filtration through BNC membrane in presence of $\mathrm{NaBH}_{4}$. (B) Absorbance of $\mathrm{MO}$ solution before and after filtration through Pd-mPDA-BNC membrane in the absence of $\mathrm{NaBH}_{4}$. 
(A)

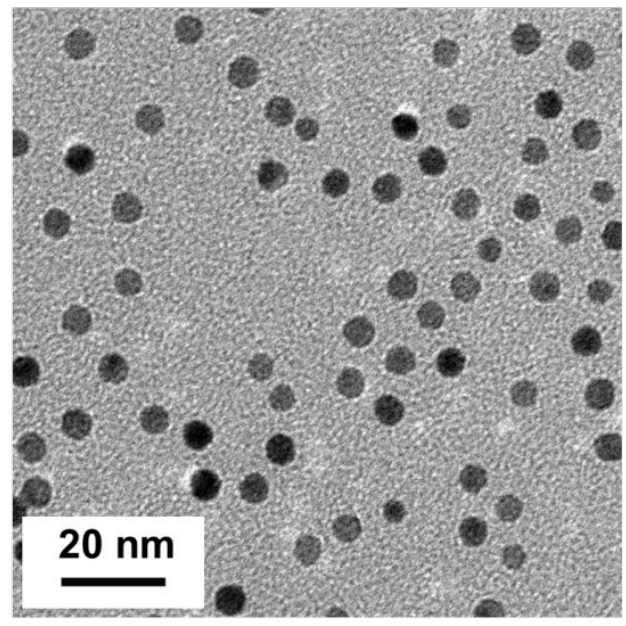

(B)

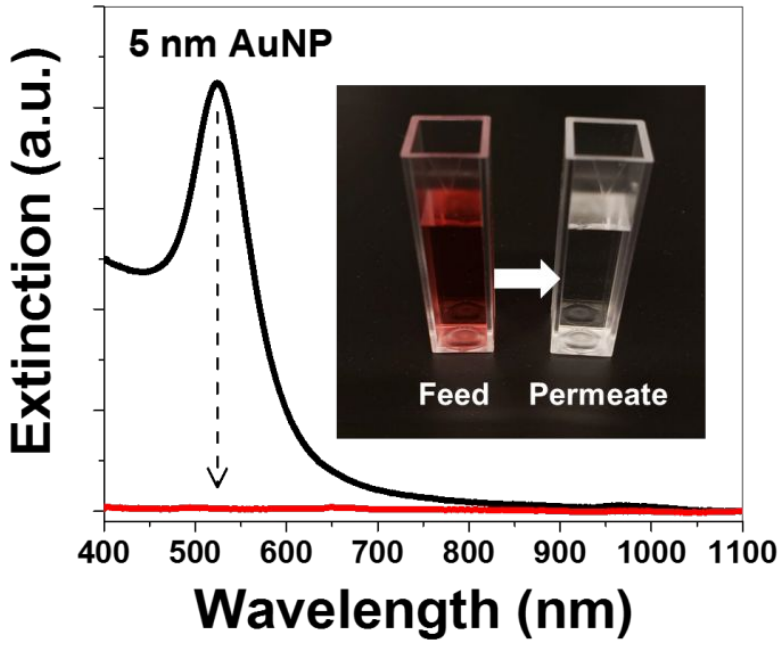

Figure S8. Particle rejection test. (A) TEM image of the $5 \mathrm{~nm}$ AuNPs used for praticles rejection test on Pd-mPDA-BNC membrane. (B) Extinction spectra of the AuNP feed solution and the permeate after filtration through Pd-mPDA-BNC membrane (Inset shows corresponding optical image of the solution). 


\section{References}

1. Zheng, Y.; Zhong, X.; Li, Z.; Xia, Y., Successive, Seed - Mediated Growth for the Synthesis of Single - Crystal Gold Nanospheres with Uniform Diameters Controlled in the Range of 5-150 nm. Particle \& Particle Systems Characterization 2014, 31 (2), 266-273. 2. $\quad$ Poletto, M.; Pistor, V.; Santana, R. M. C.; Zattera, A. J., Materials produced from plant biomass: part II: evaluation of crystallinity and degradation kinetics of cellulose. Materials Research 2012, 15, 421-427.

3. EPA, Report of the Food Quality Protection Act (FQPA) Tolerance Reassessment Eligibility Decision (TRED) for Boric Acid/Sodium Borate Salts.

https://www3.epa.gov/pesticides/chem search/reg actions/reregistration/tred PC-011001_1Jul-06.pdf. 